\title{
Resistance Training Enhances Renal Function in Experimental Renal Ischemia-Reperfusion
}

Kafashi, M ; Parnow, Abdolhossein ; Kaffashian, M R ; Knechtle, Beat

\begin{abstract}
Acute kidney injury (AKI) resulting from ischemia-reperfusion injury (IRI) is among the most common complications in hospitalized patients. In recent years, it has been argued that exercise is an approach to attenuate impairments caused by AKI. The purpose of this study was to investigate whether eight weeks of resistance training (RT) has protective effects on IRI. Thirty male Wistar rats (210-230 g) were randomly divided into four groups, including RT+ISC ( $n=7)$, RT $(n=8)$, ISC $(n=7)$, and sham $(n=8)$. Animals underwent eight weeks of RT, and 48 hours after the last training session, ischemia ( $45 \mathrm{~min}$ ) reperfusion $(24 \mathrm{~h})$ was induced. Then animals were sacrificed, and blood and kidney tissue samples were collected to measure creatinine $(\mathrm{Cr})$, blood urea nitrogen (BUN), kidney tissue damage score (KTDS), and kidney weight (KW). The results showed that IRI caused a significant increase in $\mathrm{Cr}$, BUN, KTDS, and KW (p-value <0.05), while RT decreased the severity of KTDS, Cr, and BUN remarkably. $(\mathrm{p} \leq 0.05)$. RT, however, did not attenuate KW $(\mathrm{p} \leq 0.05)$. Overall, the findings of our study provide evidence that RT can attenuate IRI-induced AKI considering enhanced biomarkers; However, further research should be conducted to make certain about the protective effects of exercise training, especially RT.
\end{abstract}

DOI: https://doi.org/10.34045/sems/2021/33

Posted at the Zurich Open Repository and Archive, University of Zurich

ZORA URL: https://doi.org/10.5167/uzh-209965

Journal Article

Published Version

Originally published at:

Kafashi, M; Parnow, Abdolhossein; Kaffashian, M R; Knechtle, Beat (2021). Resistance Training Enhances Renal Function in Experimental Renal Ischemia-Reperfusion. SEMS-journal:online.

DOI: https://doi.org/10.34045/sems/2021/33 


\title{
Resistance Training Enhances Renal Function in Experimental Renal Ischemia-Reperfusion
}

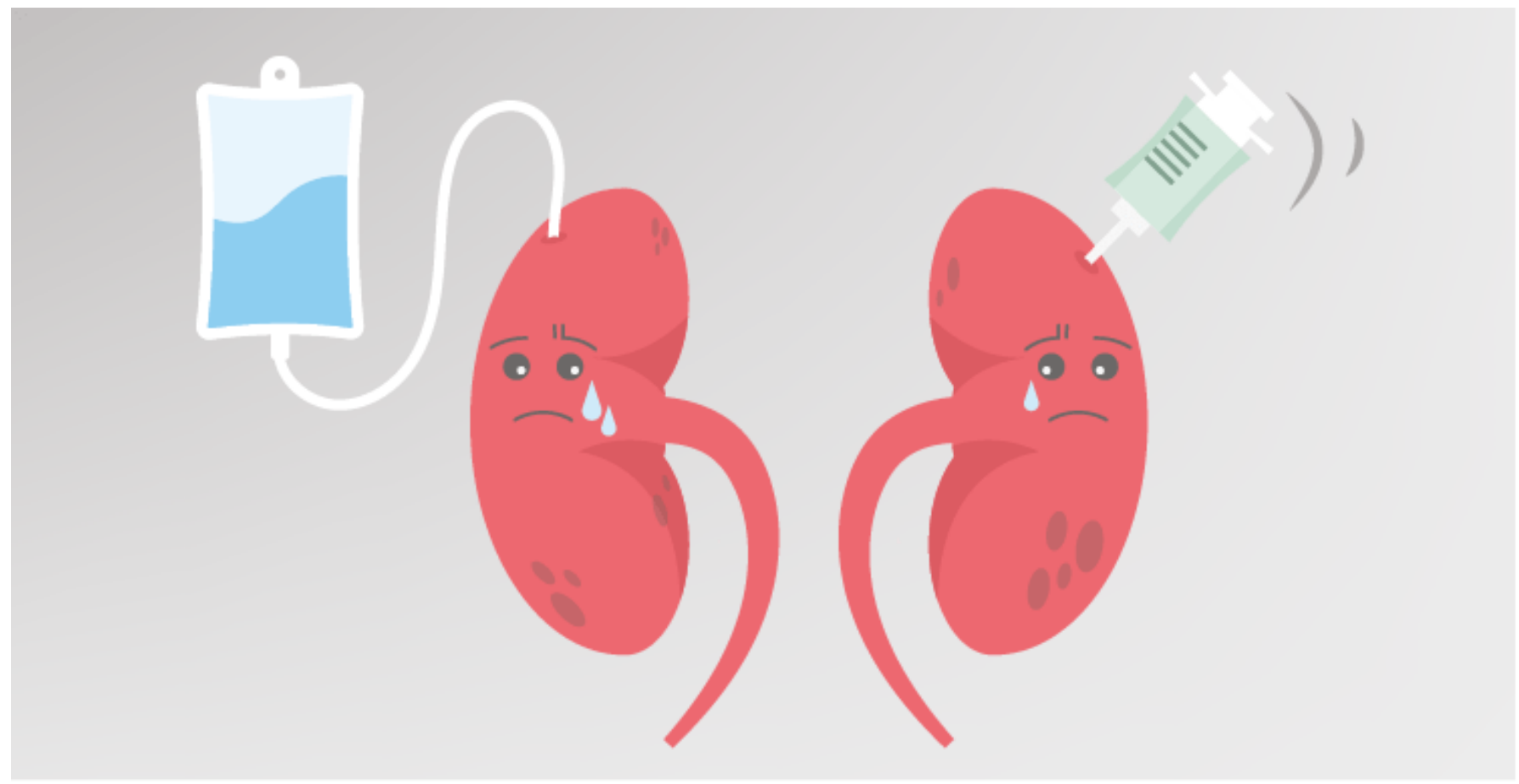

Kafashi Mina ${ }^{1}$, MSc; Parnow Abdolhossein ${ }^{1}$, PhD; Kaffashian Mohammad Reza ${ }^{2}$, PhD; Knechtle Beat ${ }^{3}$, PhD

${ }^{1}$ Department of Exercise Physiology, Faculty of Sport Sciences, Razi University, Kermanshah, Iran

${ }^{2}$ Department of Physiology, School of Medicine, Ilam University of Medical Sciences, Ilam, Iran

${ }^{3}$ Institute of Primary Care, University of Zurich, Zurich, Switzerland

\begin{abstract}
Acute kidney injury (AKI) resulting from ischemia-reperfusion injury (IRI) is among the most common complications in hospitalized patients. In recent years, it has been argued that exercise is an approach to attenuate impairments caused by AKI. The purpose of this study was to investigate whether eight weeks of resistance training (RT) has protective effects on IRI. Thirty male Wistar rats (210-230 g) were randomly divided into four groups, including RT+ISC ( $n=7)$, RT $(n=8)$, ISC $(n=7)$, and sham $(n=8)$. Animals underwent eight weeks of RT, and 48 hours after the last training session, ischemia (45 min) reperfusion ( $24 \mathrm{~h}$ ) was induced. Then animals were sacrificed, and blood and kidney tissue samples were collected to measure
\end{abstract}


creatinine (Cr), blood urea nitrogen (BUN), kidney tissue damage score (KTDS), and kidney weight (KW). The results showed that IRI caused a significant increase in Cr, BUN, KTDS, and KW (p-value <0.05), while RT decreased the severity of KTDS, Cr, and BUN remarkably. ( $\mathrm{p} \leq 0.05)$. RT, however, did not attenuate KW ( $\mathrm{p} \leq 0.05)$. Overall, the findings of our study provide evidence that RT can attenuate IRI-induced AKI considering enhanced biomarkers; However, further research should be conducted to make certain about the protective effects of exercise training, especially RT.

\section{Resumé}

L’insuffisance rénale aiguë (IRA) résultant d'une lésion d'ischémie-reperfusion (IRI) fait partie des complications les plus courantes chez les patients hospitalisés. Ces dernières années, il a été avancé que l'exercice est une approche permettant d'atténuer les problèmes causés par l'IRA. Le but de cette étude était d'examiner si huit semaines d'entraînement en résistance (RT) ont des effets protecteurs sur l'IRI. Trente rats Wistar mâles (210-230 g) ont été répartis au hasard en quatre groupes, dont RT+ISC (n=7), RT $(n=8)$, ISC $(n=7)$ et sham $(n=8)$. Les animaux ont subi huit semaines de RT, et 48 heures après la dernière session d'entraînement, une ischémie ( $45 \mathrm{~min}$ ) et une reperfusion ( $24 \mathrm{~h}$ ) ont été induites. Les animaux ont ensuite été sacrifiés, et des échantillons de sang et de tissus rénaux ont été prélevés pour mesurer la créatinine (Cr), l'urée, le score de dommages aux tissus rénaux (KTDS) et le poids des reins (KW). Les résultats ont montré que l'IRI a provoqué une augmentation significative de $\mathrm{Cr}$, de l'urée, du KTDS et du KW (valeur $\mathrm{p}<0,05$ ), tandis que RT a diminué remarquablement la sévérité du KTDS, de la Cr et de l'urée ( $\mathrm{p} \leq 0.05)$. RT n’a cependant pas atténué le KW ( $\mathrm{p} \leq 0,05)$. Dans l'ensemble, les résultats de notre étude fournissent des preuves que RT peut atténuer l'IRA induite par l'IRI en tenant compte des biomarqueurs améliorés. Des études supplémentaires devraient être menées pour vérifier les effets protecteurs de l'entraînement physique, en particulier de type résistance.

\section{Introduction}

Acute kidney injury (AKI) is described as a sudden (within hours) reduction in kidney function, which comprises both structural damage and loss of function [1]. Surgery, sepsis, low cardiac output, hypervolemia, rhabdomyolysis, urinary obstruction, and drug toxicity are the main contributing factors of AKI [3]. AKI resulting from ischemia-reperfusion injury (IRI) is among the most common complications in hospitalized patients [2]. About 7-18\% of all hospitalized patients suffer from AKI, and about 35\% of intensive care are struggling with this problem [3].

IRI includes two parts: the ischemia and reperfusion phases [4]. In the ischemia phase, anoxic injury happens and energy contents (ATP) of cells reduce due to declined energy production in the mitochondria

[5]. Therefore, blood $\mathrm{PH}^{+}$reduces due to ATP production through the glycolytic process, and releasing $\mathrm{H}^{+}$by impaired lysosomes [6]. Following ions impairment, cytoplasmic $\mathrm{Na}^{+}$and $\mathrm{Ca}^{+}$concentrations are also increased, associated with osmotic edema and activation of phospholipids and proteases [7]. In the second phase, acute tubular necrosis occurs, which is associated with inflammation and oxidative stress, and can intensify renal injury and contribute to loss of renal function [4,6]. AKI is recognized by an abrupt decrease in the glomerular filtration rate (GFR) and revealed by an increase in serum creatinine concentration [8]. Pro-inflammatory cytokines, namely TNF- and IL-6 generated from renal tubule cells, 
have been recognized as major contributors of ischemia-reperfusion (IR) $[9,10]$.

A review study has reported that physical activity can serve as the primary prevention of several chronic diseases [11]. Improving health outcomes by regular resistance exercise, which involves large muscle groups, is well-established in individuals who suffer from chronic kidney disease (CKD) [12]. It has also been shown that resistance exercise can increase muscle strength in pre-dialysis, dialysis, and post-dialysis patients [13-15]. Besides, it can prevent muscle wasting without creating a large number of inflammatory responses [16]. Castaneda et al. noticed that their resistance training (RT) program remarkably degraded the amount of circulating C-reactive protein (CRP) and Interleukin 6 (IL-6) levels in comparison with the control group [17]. They also recognized a reverse relation between longitudinal alternation in serum IL-6 levels and skeletal muscle fiber size and strength. This intimates that the anabolic incentive of RT may inverse the catabolic phase of CKD by reducing chronic inflammation [17].

Further studies have shown that aerobic exercise can have protective effects on IR-induced AKI, and enhances many biomarkers such as tissue damage, the serum creatinine level, and the serum of malondialdehyde level, and results presented significant changes in serum creatinine level [18,19]. Recent studies mostly have targeted the influences of resistance exercise on the human, through investigating the physical biomarkers in different stages of the kidney diseases, and based on our knowledge there are few studies assessing the kidney function due to resistance exercise adaptation especially in acute kidney disease, and the effects of RT on AKI resulted from IR outcomes are unknown [20,21]. Therefore, we conducted the present study, and the hypothesis is that 8 weeks of RT can protect the kidney of IR-induced AKI in male Wistar rats.

\section{Materials and methods}

\section{Experimental Design}

Thirty male (210-230 grams) Wistar rats (animal center, Ilam university of medical science, Ilam, Iran) were used in the current study. All animals were housed every four in a cage and weighed once a week. Water and food were available for all of them freely, and a 12:12-hr light/dark cycle was used to keep the animals. All experimental procedures were followed by the NIH guidelines for the treatment of animals, and approved by the Committee of Ilam University of Medical Sciences (IR.MEDILAM.REC.1398.117). Animals were randomly assigned as four groups including, group I underwent RT protocol, and after 48 hours, kidneys were clamped for 45 minutes followed by 24 hours of reperfusion then sacrificed (RT+ISC), group II was done RT and sacrificed 48 hours after the last training session (RT), group III in which RT protocol was not applied and just kidneys were clamped for 45 minutes followed by 24 hours of reperfusion (ISC), and group IV in which nor RT protocol was applied neither IR was induced (sham). Animals were familiarized with the ladder and the attached weight to their tails for three consecutive days, then the main protocol started at the fourth day and continued for 8 weeks. The training protocol was repeated once every 3 days for 8 weeks, totally 20 training. 48 hours after the last training session ischemia was induced and 24 hours later were sacrificed in order to collecting the tissue and blood samples. A summary of the entire protocol process of this research is given in Figure 1. 


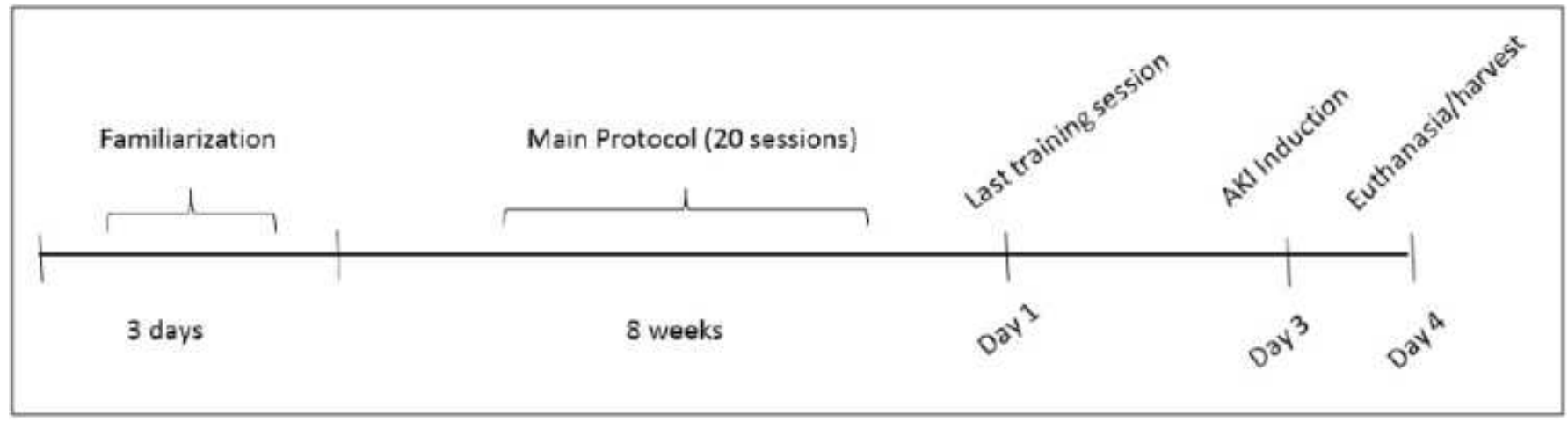

Figure 1

\section{Exercise training Protocol}

The groups I and II were familiarized with the ladder (1.13 $0.18 \mathrm{~m}, 2-\mathrm{cm}$ grid, $80^{\circ}$ incline), while a load was attached to their tails. The ladder length was suitable for 8-12 movements (repetitions) per climb (set). At the top of the ladder, a chamber $(20 * 20 * 20)$ was located for animals to rest. Animals compelled to climb by using mild shock, and this procedure repeated until rats climbed up voluntarily (shown in Fig. 2) [22].

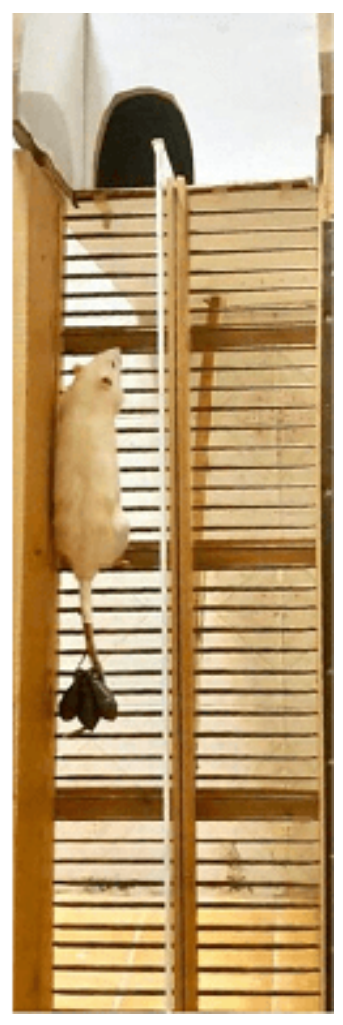

Figure 2

The main protocol started following three days of familiarization. The first training session in which the maximum carrying capacity (MCC) was measured, rats carried a weight of $75 \%$ of their body weight in the 
first climb, then $30 \mathrm{~g}$ were added subsequently. This procedure continued until rats could not climb the entire ladder successfully even by inducing three consecutive single shocks, thereby the last successful climb was noted as a MCC. Subsequent resistant training sessions consisted of 4 to 8 climbs, which the loads arranged 50\%, 75\%, 90\%, 100\% of their MCC, respectively. In the next climbs $30 \mathrm{~g}$ was added to achieve a new MCC. This progressive protocol continued for 8 weeks (20 sessions) in total [22].

\begin{tabular}{|l|l|}
\hline Grade & Injury (involvement percentage) \\
\hline 0 & Normal kidney \\
\hline 1 & Slight damage $(<5 \%)$ \\
\hline 2 & Mild damage $(5-25 \%)$ \\
\hline 3 & Moderate damage $(25-75 \%)$ \\
\hline 4 & Severe damage $(>75 \%)$ \\
\hline
\end{tabular}

\section{Table 1: Kidney Tissue Damage Score Grading Scale}

\section{AKl induction}

Group I was provided for ischemia surgery 48 hours after the last training session. Animals were anesthetized by $10 \mathrm{mg} / \mathrm{kg}$ of xylazine and $100 \mathrm{mg} / \mathrm{kg}$ of ketamine hydrochloride intraperitoneally, then the abdominal area was shaved and opened under sterile condition. Ischemia was induced by bilateral clamping with hysterectomy clamp forceps. After $45 \mathrm{~min}$ clamps were removed, and kidneys returned into the abdomen. Afterward, incisions stitched, and the rats were allowed to recover with reperfusion for $24 \mathrm{~h}$. This progression applied to the positive control group the day after [23].

\section{Measurement and Histopathological Procedures}

Animals were re-anesthetized 24 hours after ischemia surgery, and blood samples were taken from the heart, then the blood samples centrifuged at $6000 \mathrm{rpm}$, and the serums were collected and stored in $-80^{\circ} \mathrm{C}$. Afterward, animals were sacrificed via anesthetic overdose, and both kidneys removed and weighed. The left kidney was kept in a 10\% neutral formalin solution to histopathological staining, and the right kidney fixed in a $1.5 \mathrm{cc}$ microtube stored at $-80^{\circ} \mathrm{C}$ until assayed. The same protocol was performed in sham, and 48 hours after the last training session in groups II. The serum level of $\mathrm{Cr}$ and BUN measured by using quantitative diagnostic kits (Pars Azmoon, Iran). Hematoxylin and eosin staining method was applied to record the kidney tissue damage score (KTDS), and reported via the 0-4 grading scale as described in table 1 [24], based on a subjective impression of the alternations, such as tubular dilatation and simplification, tubular cell swelling and necrosis, tubular casts, and intraluminal cell debris with infiltration of inflammatory cells. 


\section{Statistical Analyses}

Data expressed as mean \pm SEM. One-way ANOVA were utilized to analyze the kidney weight $(\mathrm{KW})$ among the groups. To compare the KTDS, BUN, $\mathrm{Cr}$, and $\triangle \mathrm{BW}$ among the groups, Kruskal Wallis and Mann-Whitney U tests applied. Statistical analysis was performed by 23 SPSS software and a significance level of less than 0.05 ( $p$-value $\leq 0.05$ ).

\section{Results}

The results showed a significant elevation in Cr, BUN, KTDS, and KW in the ISC group (p-value <0.05). A remarkable decrease was observed in the severity of KTDS and attenuation of Cr and BUN in the group $\mathrm{RT}+\mathrm{ISC}(\mathrm{p} \leq 0.05) . \mathrm{KW}$, however, was not attenuated in the RT+ISC group $(\mathrm{p} \leq 0.05)$. The mean and standard deviation of measured biomarkers in this study is given in Table 2.

\begin{tabular}{|c|c|c|c|c|}
\hline & Sham & ISC & RT & RT+ISC \\
\hline BUN (mg/dl) & $63.11 \pm 11.50$ & $110.18 \pm 17.15^{*}$ & $68.56 \pm 24.64^{* * *}$ & $89.41 \pm 24.64$ \\
\hline $\mathrm{Cr}$ (mg/dt) & $0.69 \pm 0.05$ & $0.94 \pm 0.10^{*}$ & $0.78 \pm 0.09$ & $0.80 \pm 0.09$ \\
\hline$\Delta B W[g r]$ & $73.37 \pm 20.55$ & $72.14 \pm 13.84$ & $77.75 \pm 16.09$ & $92.00 \pm 13.47$ \\
\hline $\mathrm{KW}$ (gr) & $0.42 \pm 0.04$ & $0.50 \pm 0.07^{* *}$ & $0.41 \pm 0.01$ & $0.48 \pm 0.04^{* *}$ \\
\hline
\end{tabular}

Table 2: Mean $\pm \mathrm{S}$ of $\mathrm{BUN}, \mathrm{Cr}, \triangle \mathrm{BW}$, and $\mathrm{KW}$ in the four experimental groups.

\section{Changes of Serum Levels of BUN and $\mathrm{Cr}$}

There were significantly observed an increase in the ISC group in comparison with sham for the serum level of BUN ( $\mathrm{P}=0.001, \mathrm{~d}=3.22)$, and $\mathrm{Cr}(\mathrm{P}=0.001, \mathrm{~d}=3.16)$. However, no significant change in the RT+ISC group compared to the ISC group was observed in these parameters $(\mathrm{P}<0.05)$. There was not a significant difference between the RT+ISC group and sham in BUN ( $\mathrm{P}=0.154)$ and $\mathrm{Cr}(\mathrm{P}=0.231)$ (shown in Fig. 3). In total, RT could attenuate BUN and $\mathrm{Cr}$ in the RT+ISC group. 


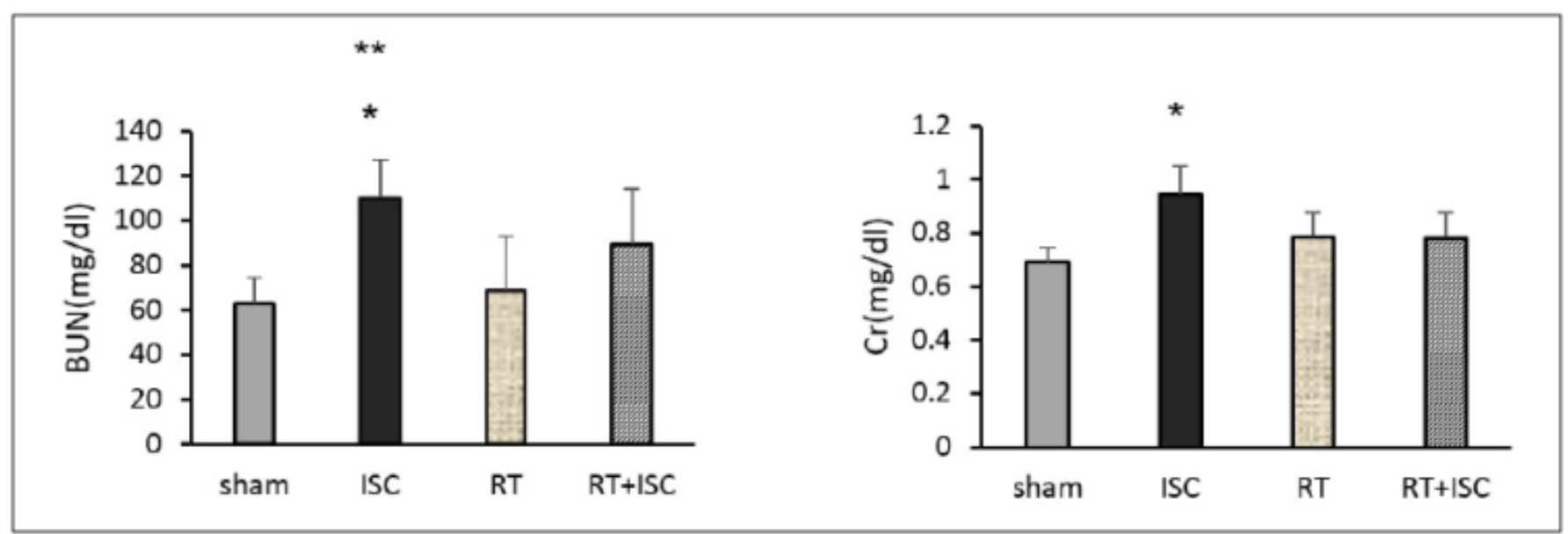

Figure 3: The serum level of Blood Urea Nitrogen (BUN) and Creatinine (Cr). * significant difference vs. sham; ** significant difference vs. RT group

\section{Changes of KW, KTDS and BW}

Significant differences were observed in the RT+ISC group vs. RT group ( $\mathrm{P}=0.005, \mathrm{~d}=1.83$ ) and RT group vs. ISC group ( $\mathrm{P}=0.026, \mathrm{~d}=2.50)$ in KW. Furthermore, the ISC group was higher than the other groups in KTDS considerably, and the significant difference between the RT+ISC group and the ISC group was observed $(\mathrm{P}<0.05)$. However, there were not observed any significant differences among the groups in $\Delta \mathrm{BW}$ (shown in Fig. 4). The samples of kidney tissue images are shown in Figure 5.

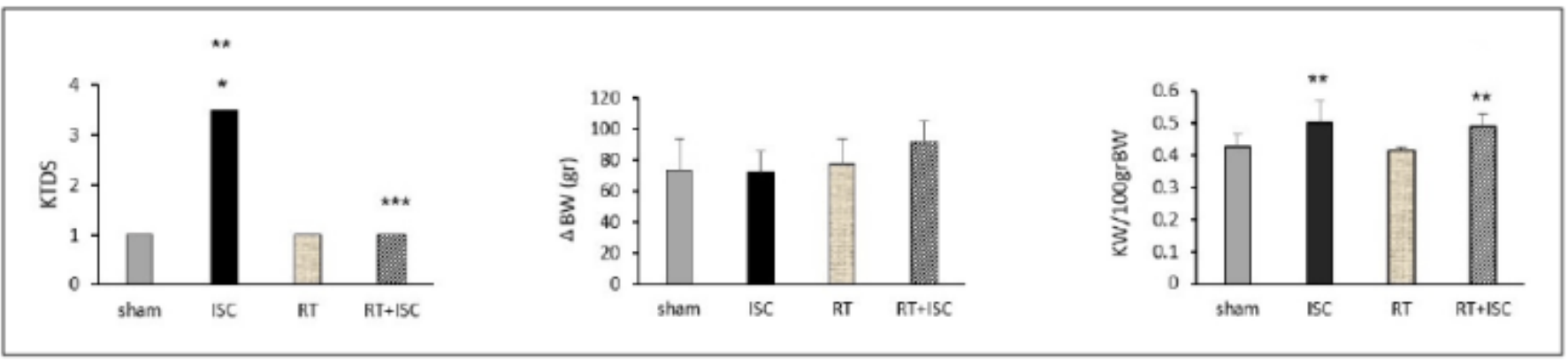

Figure 4: Kidney Weight (KW), Kidney Tissue Damage Score (KTDS), Delta-Body Weight ( $\triangle$ BW). * significant difference vs. sham; ** significant difference vs. RT group; *** significant difference vs. positive control group 

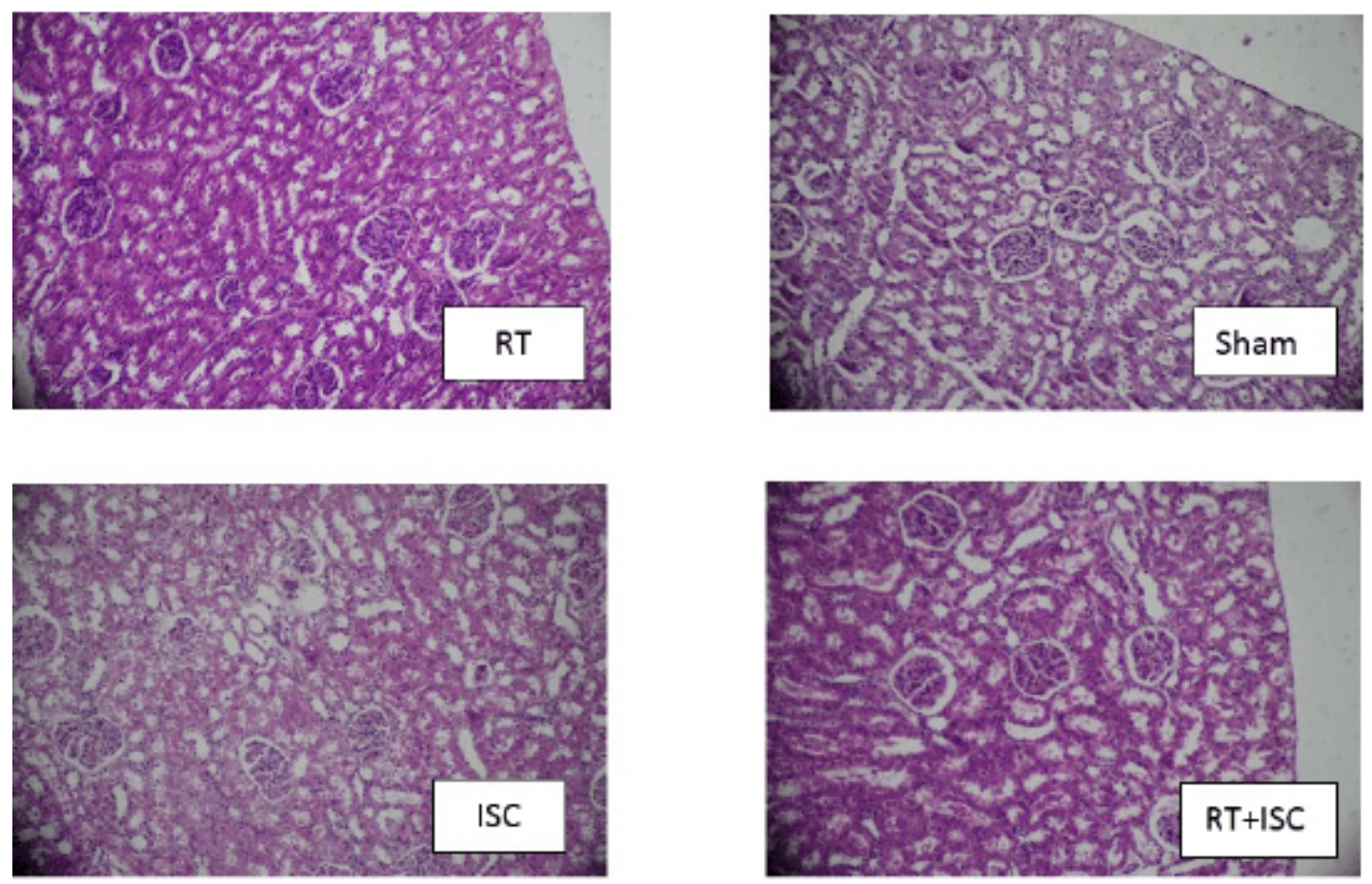

Figure 5: The images of Kidney Tissues Stained in order to Survey Tissue Damage (tubular dilatation and simplification, tubular cell swelling and necrosis, tubular casts, and intraluminal cell debris) in the Kidney of the RT+ISC (ischemia-reperfusion were induced after for 8 weeks of resistance training), RT (resistance training were applied for 8 weeks), ISC (ischemiareperfusion were induced), and sham Groups.

\section{Maximal Carrying Capacity}

Animals recorded a new MCC in each session. The average MCC in the first session was 263.6 grams and improved to 613.5 grams in the last session which demonstrates $232.7 \%$ of progression (shown in Fig. 6). 


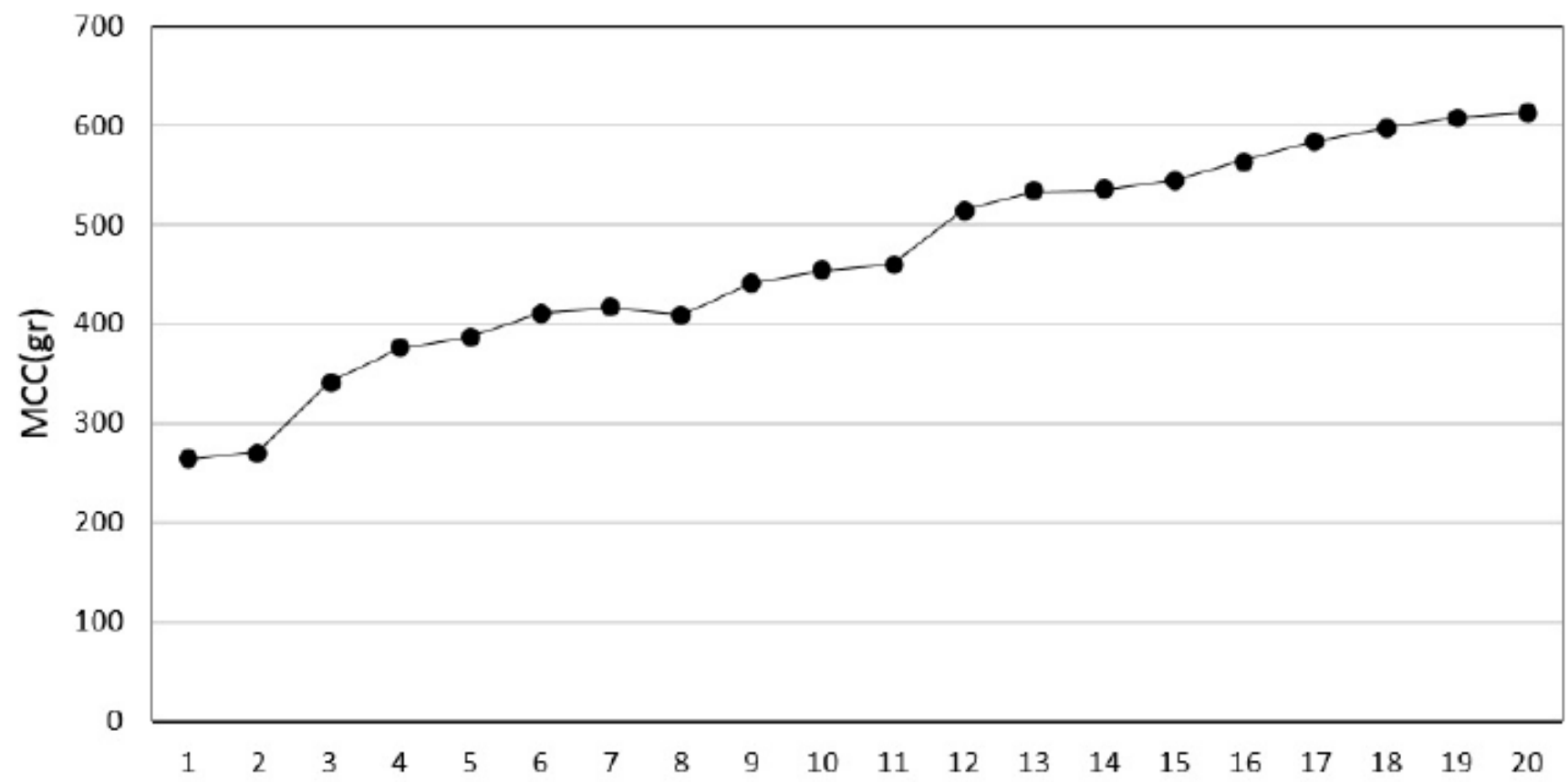

Figure 6: MCC=Maximal carrying capacity, Over the course of 8 weeks (20 training sessions) the animal's MCC increased 232.7\%, Values are expressed as mean.

\section{Discussion}

The current study's main purpose was to investigate whether RT could alleviate impairments resulting from AKI after IR induction. According to our knowledge, this was the first research to investigate RT's effects on induced IRI.

This study demonstrated a significant increase in the serum level of $\mathrm{Cr}$ and BUN $24 \mathrm{~h}$ after ischemia surgery ( $45 \mathrm{~min}$ of ischemia followed by $24 \mathrm{~h}$ of reperfusion). BUN and $\mathrm{Cr}$ are the nitrogenous waste product of urea, and urea is made from protein catabolism [25], excreted from the body, particularly by the kidneys. Analysis of its concentration in urine and blood has been a clinical application of renal function recognition for many years [26]. Our findings are in accordance with previous studies and support that $\mathrm{Cr}$ and BUN reach a peak 24 hours after IR and gradually reduce in a week [18,27-30]. In our study, significant changes were not observed in the RT+ISC group compared to the sham, which manifested the protective effects of RT in confronting the biomarkers, as mentioned earlier to some extent. In other words, RT may cause a quicker reduction after IR in these factors. It is well accepted that Cr's concentration is correlated with the fractional excretion of arginine vasopressin (AVP) [31]. Studies have shown that exercise training can attenuate renal dysfunction by downregulating AVP and renal Aquaporin-2 (AQP-2) expression [32]. AVP and AQP2 play a significant role in water retention and are strongly linked to kidney disorders [32]. Exercise training likely activates angiotensin-converting enzyme (ACE) inhibitors, and ACE inhibitors downregulate AVP expression and AQP-2 mRNA [33]. As it seems water immersion enhances renal function, it can be concluded that exercise training can positively affect kidney function in that way. Our findings were in accordance with previous studies in which exercise training can ameliorate BUN and $\mathrm{Cr}[32,34,35]$. On the other hand, some studies that compared sedentary and physically active individuals have reported that participants with physical activity have a higher 
amount of BUN and $\mathrm{Cr}$ in their serum. They linked the results to the larger muscle mass of active participants [36,37].

Moreover, after IR, kidney edema is likely related to kidney tissue edema, cell proliferation, water, and salt retention resulting from renal tubule destruction [38,39]. In the present study, KW increased in the ISC group and RT+ISC group significantly, which means IR increases the kidney weight. This finding is wellestablished by previous studies [40,41]. One mechanism of cell proliferation after IR in the kidney may link to activation of the mammalian target of rapamycin (MTOR) in the reperfusion phase of IR [42]. mTOR is a threonine protein kinase that regulates vital signaling pathways and is included in growth stimuli and cellcycle progress [43], and activity is low or absent in the normal kidney. However, it is speculated that the mTOR's abrupt increase is in response to the sudden availability of growth factors, amino acids, and cellular ATP after a period of intense deficiency at the ischemia phase [42]. In our study, however, kidney hypertrophy in the RT+ISC group was not lower than the ISC group, even though exercise may downregulate the expression of AVP and AQP-2. Although the evidence for RT functions' possible mechanisms in induced IR is limited, kidney hypertrophy after IR in the RT+ISC group is likely due to the activation of mTOR pathways. Although adaptations to exercise principally happen in skeletal muscle, the influence of exercise can affect other tissues via systemic control of energy homeostasis and metabolism [44]. Nevertheless, endurance exercise inhibits the mTOR expression via activating adenosine monophosphate-activated protein kinase (AMPK) [44]; RT may have different effects on non-muscle tissues. Our findings of BUN and $\mathrm{Cr}$ was confirmed by pathological data. Histopathological analysis revealed that IR induces extensive degenerative mutations of glomeruli and renal tubules by mechanisms such as oxidative stress and apoptosis, and our histopathological examination designated that RT attenuates KTDS as significant differences between the RT+ISC group and the ISC group were observed, which is in agreement with a study by Vafamand et al. [18].

Throughout the current study's exercise training protocol, despite a remarkable increase in the trained rats' ability to climb the ladder with progressively heavier loads (the average progression of 232.7\%), there were not observed significant differences among groups in their body weight. The possible explanation of this fact is that the ability to lift progressively heavier loads likely was only due to some enhanced neural responses [45]. Our finding was in accordance with the research by Hornberger et al. and Duncan et al. in which progressive and long-term RT were applied on rats, respectively [22,46].

Overall, the current research illustrates that 8 weeks of RT has a modulator effect on AKI risk factors resulting from IR in male Wistar rats. Future studies, however, are necessary to prove the benefits of exercise training, especially RT on AKI. Future preclinical studies should evaluate GFR and malondialdehyde as two crucial kidney biomarkers. Clinical studies are also required to determine whether trained patients show moderated renal impairment after AKI resulting from IR.

\section{Practical implication}

We compared sedentary and physically active animals and investigated whether resistant exercise can protect their kidneys from some sudden kidney injuries such as ischemia-reperfusion. As our study confirms the positive effects of resistant exercise on renal function after acute kidney injuries, it is recommended to healthy individuals put resistant training on their physical activity schedule. 


\title{
Acknowledgment
}

The authors thank Dr. M. Maleki and Ms. N. Molai for their skillful technical support.

\section{Conflict of interest statement}

The authors declare that they do not have conflict of interest.

\section{Ethics approval and informed consent}

All experimental procedures were approved by the Institutional Animal Care and Use Committee of the Medical University of Ilam (IR.MEDILAM.REC.1398.117).

\section{Funding sources}

There is no financial support for this work.

\section{Author contributions}

MK contributed in literature searching and data collection AP contributed as supervisor and make final decision. MRK contributed to design research and preparation manuscript, and BK contributed as cosupervisor and final edition and managed.

\section{Corresponding author}

\author{
Abdolhossein Parnow, PhD \\ Faculty of Sports Sciences, Razi University, Kermanshah, Iran \\ Street Name \& Number: \\ Tagh-e-Bostan, University St. \\ Work phone: +98- 83-34283275 - 83-34279265 \\ P. O. Box 6714414874 \\ Fax: +98- 83-34274585 \\ E-mail address: parnowabdolhossein@gmail.com $\square$
}

\section{References}

1. Makris K, Spanou L. Acute Kidney Injury: Definition, Pathophysiology and Clinical Phenotypes. Clin Biochem Rev. 2016;37(2):85-98.

2. Hoste EA, Schurgers M. Epidemiology of acute kidney injury: how big is the problem? Crit Care Med. 2008;36(4 Suppl):S146-51.

3. Paladino JD, Hotchkiss JR, Rabb H. Acute kidney injury and lung dysfunction: a paradigm for remote organ effects of kidney disease? Microvasc Res. 2009;77(1):8-12.

4. de Groot H, Rauen U. Ischemia-reperfusion injury: processes in pathogenetic networks: a review. Transplant Proc. 2007;39(2):481-4.

5. Devarajan P. Cellular and molecular derangements in acute tubular necrosis. Curr Opin Pediatr. 
2005;17(2):193-9.

6. Francescato HDC, Almeida LF, Reis NG, Faleiros CM, Papoti M, Costa RS, et al. Previous Exercise Effects in Cisplatin-Induced Renal Lesions in Rats. Kidney Blood Press Res. 2018;43(2):582-93.

7. Kosieradzki M, Rowinski W. Ischemia/reperfusion injury in kidney transplantation: mechanisms and prevention. Transplant Proc. 2008;40(10):3279-88.

8. Levey AS, James MT. Acute Kidney Injury. Ann Intern Med. 2017;167(9):ITC66-ITC80.

9. Donnahoo K, Meldrum D, Shenkar R, Chung C, Abraham E, Harken A. Early renal ischemia, with or without reperfusion, activates NFkB and increases TNF- $a$ bioactivity in the kidney. The Journal of urology. 2000;163:1328-32.

10. Kielar M, John R, Bennett M, Richardson J, Shelton J, Chen L, et al. Maladaptive Role of IL-6 in Ischemic Acute Renal Failure. Journal of the American Society of Nephrology: JASN. 2005;16:3315-25.

11. Booth FW, Roberts CK, Laye MJ. Lack of exercise is a major cause of chronic diseases. Compr Physiol. 2012;2(2):1143-211.

12. Heiwe S, Jacobson SH. Exercise training in adults with CKD: a systematic review and meta-analysis. Am J Kidney Dis. 2014;64(3):383-93.

13. Mallamaci F MM, Bolignano D, Bertoli S, Messa P, Zuccalà A, Fatuzzo P, Rapisarda F, Lombardi L, Cupisti A, Fuiano G, Torino C, Baggetta R, Tripepi G, Catizone L, Zoccali C. A personalized, lowintensity, easy to implement, home exercise program improves physical performance in dialysis patients: the Exercise Introduction to Enhance Performance in Dialysis (EXCITE) Trial. Dialysis: Identifying Risk Factors and Improving Noncardiovascular Outcomes. J Am Soc Nephrol. 2014.

14. Painter PL, Hector L, Ray K, Lynes L, Dibble S, Paul SM, et al. A randomized trial of exercise training after renal transplantation. Transplantation. 2002;74(1):42-8.

15. Rossi AP, Burris DD, Lucas FL, Crocker GA, Wasserman JC. Effects of a renal rehabilitation exercise program in patients with CKD: a randomized, controlled trial. Clin J Am Soc Nephrol. 2014;9(12):2052-8.

16. Kafashi M, Kaffashian MR, Nematbakhsh M, Maleki M, Safari T. Does exercise training attenuate cisplatin nephrotoxicity? J Renal Inj Prev. 2020;9(4):e29-e.

17. Castaneda C, Gordon PL, Parker RC, Uhlin KL, Roubenoff R, Levey AS. Resistance training to reduce the malnutrition-inflammation complex syndrome of chronic kidney disease. American journal of kidney diseases: the official journal of the National Kidney Foundation. 2004;43(4):607-16.

18. Effatsadat Vafamand LB, Ardeshir Talebi, Mehdi Nematbakhsh. The role of L-arginine and aerobic exercise in experimental renal ischemia reperfusion injury in male and female rats. Hormozgan Medical Journal. 2017;21.

19. Saad RA. Long term exercise preconditioning protects against renal dysfunction after ischemia reperfusion injury in rat kidneys. Journal of American Science. 2014;10(6).

20. Ito S, Shinbo H, Boku M, Uchida J, Yamamoto J, Sato S, et al. [Effect of exercise on rats with renal injury]. Nihon Jinzo Gakkai Shi. 1992;34(3):295-9.

21. Poortmans JR, Vanderstraeten J. Kidney function during exercise in healthy and diseased humans. An update. Sports Med. 1994;18(6):419-37.

22. Hornberger TA, Jr., Farrar RP. Physiological hypertrophy of the FHL muscle following 8 weeks of progressive resistance exercise in the rat. Can J Appl Physiol. 2004;29(1):16-31.

23. Williams P, Lopez H, Britt D, Chan C, Ezrin A, Hottendorf R. Characterization of renal ischemiareperfusion injury in rats. Journal of pharmacological and toxicological methods. 1997;37(1):1-7.

24. Malek M, Nematbakhsh M. The preventive effects of diminazene aceturate in renal ischemia/reperfusion injury in male and female rats. Advances in preventive medicine. 2014;2014:740647.

25. Baum N, Dichoso CC, Carlton CE. Blood urea nitrogen and serum creatinine. Physiology and interpretations. Urology. 1975;5(5):583-8. 
26. AO. H. BUN and Creatinine. In: Walker HK HW, Hurst JW, editor. Clinical Methods: The History, Physical, and Laboratory Examinations. 3rd ed. Boston: Butterworths; 1990.

27. Hesketh E, Czopek A, Clay M, Borthwick G, Ferenbach D, Kluth D, et al. Renal Ischaemia Reperfusion Injury: A Mouse Model of Injury and Regeneration. Journal of visualized experiments: JoVE. 2014.

28. Kim M-G, Koo T, Yan J-J, Lee E, Han K, Jeong J, et al. IL-2/Anti-IL-2 Complex Attenuates Renal Ischemia-Reperfusion Injury through Expansion of Regulatory T Cells. Journal of the American Society of Nephrology: JASN. 2013;24.

29. Malek M, Nematbakhsh M. Renal ischemia/reperfusion injury; from pathophysiology to treatment. Journal of renal injury prevention. 2015;4:20-7.

30. Moningka NC, Cunningham MW, Sterling M, West CA, Verlander JW, Croker BP, Ahlgren J, Hayward L, Baylis C. Effects of voluntary wheel running on the kidney at baseline and after ischaemia-reperfusion-induced acute kidney injury: a strain difference comparison. J Physiol. 2012:1313-24.

31. Nonoguchi H, Takayama M, Owada A, Ujiie K, Yamada T, Nakashima O, et al. Role of urinary arginine vasopressin in the sodium excretion in patients with chronic renal failure. Am J Med Sci. 1996;312(5):195-201.

32. Lin Q-Q, Lin R, Ji Q-L, Zhang J, Wang W-R, Yang L-N, et al. Effect of exercise training on renal function and renal aquaporin-2 expression in rats with chronic heart failure. Clinical and experimental pharmacology \& physiology. 2011;38.

33. Wong NL, Tsui JK. Upregulation of vasopressin V2 and aquaporin 2 in the inner medullary collecting duct of cardiomyopathic hamsters is attenuated by enalapril treatment. Metabolism: clinical and experimental. 2002;51(8):970-5.

34. Chen J, Muntner P, Hamm L, Jones D, Batuman V, Fonseca V, et al. The Metabolic Syndrome and Chronic Kidney Disease in U.S. Adults. Annals of internal medicine. 2004;140:167-74.

35. Straznicky NE, Grima MT, Lambert EA, Eikelis N, Dawood T, Lambert GW, et al. Exercise augments weight loss induced improvement in renal function in obese metabolic syndrome individuals. J Hypertens. 2011;29(3):553-64.

36. Baxmann AC, Ahmed MS, Marques NC, Menon VB, Pereira AB, Kirsztajn GM, et al. Influence of muscle mass and physical activity on serum and urinary creatinine and serum cystatin $\mathrm{C}$. Clin J Am Soc Nephrol. 2008;3(2):348-54.

37. Heymsfield SB, Arteaga C, McManus C, Smith J, Moffitt S. Measurement of muscle mass in humans: validity of the 24-hour urinary creatinine method. Am J Clin Nutr. 1983;37(3):478-94.

38. Bellomo R, Kellum JA, Ronco C. Acute kidney injury. Lancet. 2012;380(9843):756-66.

39. Ouriel K, Smedira NG, Ricotta JJ. Protection of the kidney after temporary ischemia: free radical scavengers. J Vasc Surg. 1985;2(1):49-53.

40. Basile DP, Yoder MC. Renal endothelial dysfunction in acute kidney ischemia reperfusion injury. Cardiovasc Hematol Disord Drug Targets. 2014;14(1):3-14.

41. Hostetter TH. Progression of renal disease and renal hypertrophy. Annu Rev Physiol. 1995;57:263-78.

42. Lieberthal W, Levine JS. The role of the mammalian target of rapamycin (mTOR) in renal disease. J Am Soc Nephrol. 2009;20(12): 2493-502.

43. Rodriguez Perez JC. The role of mTOR inhibitors in renal diseases. Nefrologia. 2011;31(3):251-5.

44. Agostini D, Natalucci V, Baldelli G, De Santi M, Donati Zeppa S, Vallorani L, et al. New Insights into the Role of Exercise in Inhibiting mTOR Signaling in Triple-Negative Breast Cancer. Oxid Med Cell Longev. 2018;2018:5896786.

45. Mason J, Frazer AK, Avela J, Pearce AJ, Howatson G, Kidgell DJ. Tracking the corticospinal responses to strength training. European Journal of Applied Physiology. 2020;120(4):783-98.

46. Duncan ND, Williams DA, Lynch GS. Adaptations in rat skeletal muscle following long-term resistance exercise training. Eur J Appl Physiol Occup Physiol. 1998;77(4):372-8. 
